\title{
Prevalence of Helicobacter pylori infection and its association with blood groups in patients presenting epi-gastric pain in Umaru Shehu ultra- modern hospital, Maiduguri, Nigeria
}

\author{
${ }^{1}$ Ali, A.G., ${ }^{2}$ Buba, F., ${ }^{1 *}$ Isa, M.A., ${ }^{1}$ Mohammed, M.M., ${ }^{3}$ Ali, A.M. \& ${ }^{1}$ Gubio, F.A. \\ ${ }^{l}$ Department of Microbiology, Faculty of Science, University of Maiduguri, Borno State, Nigeria, ${ }^{2}$ Department of \\ Biochemistry, Faculty of Science, University of Maiduguri, Borno State, Nigeria, ${ }^{3}$ Department of Internal Medicine, Umaru \\ Shehu Ultra-Modern Hospital Maiduguri, Borno State, Nigeria.
}

*Corresponding author: mustafaisa@unimaid.edu.ng, +2348032069491

\begin{abstract}
Helicobacter pylori is a gram-negative bacterium that causes peptic ulcer and is also involved in gastric mucosa-associated lymphoid tissue lymphomas. The objective of the present study was to determine seroprevalence of Helicobacter pylori among patients complaining of epigastric pain at Umaru Shehu ultra-modern hospital Maiduguri, Nigeria. A rapid diagnostic cassette test kit for the qualitative detection of Helicobacter pylori was used in this study. A random sampling technique was used to collect blood samples and obtain other demographic variables that include sex, age and blood group which are considered as risk factors for contracting Helicobacter pylori. Out of the 50 patients tested, $45(90.0 \%)$ were positive. The positive patients comprised 10 out of 12 males (83.3\%) and 35 out of 38 females $(92.1 \%)$. Patients within the age groups 10$20,31-40$ and $>50$ years had a prevalence of $100 \%$ each, while patients between 21-30 years and those 41-50 years had a prevalence of $88.9 \%$ and $62.5 \%$ respectively. When their blood groups were considered, the AB group had a prevalence of $100 \%$ followed by the A group (95\%) while the $\mathrm{O}$ and B groups had $90.5 \%$ and $75 \%$, respectively. Patients complaining of epigastric pain should be screened for Helicobacter pylori, particularly in early cases and among people living in clusters or under inadequate sanitary conditions, such as internally displaced persons.
\end{abstract}

Keywords: ABO blood group, epigastric pain, Helicobacter pylori, peptic ulcer disease.

\section{INTRODUCTION}

Helicobacter pylori ( $H$. pylori) is a motile, gram-negative, microaerophilic spiral-shaped and flagellated bacterium. Its flagella are 4 to 6 in number and its ecological niche is the human stomach (Morris et al., 1991). It is endemic in Africa and Asia with the two continents contributing two-thirds of the disease burden in the world. There has been association of $\mathrm{H}$. pylori with gastritis and myriad of evidence has now been shown that the bacterium causes peptic ulcers and is also involved in the development of gastric mucosaassociated lymphoid tissue [MALT] lymphoma (Forman $e t$ al., 1990; Morris et al., 1991). Disease caused by bacterium has been established as the etiologic factor in the development of gastric ulcer cancer. Thus, it was designated as Class 1 carcinogen by the WHO (IARC, 1994; Alvarado, 2013). In developing countries, $70-90 \%$ of the population often contract $H$. pylori infections which are mostly acquired during childhood while the prevalence is lower in the developed countries, ranging from $30 \%$ to $40 \%$ (Saad et al., 2008).

The ABO blood group system is the most significant in human blood transfusion. The blood group antigens present on RBC are permanent, fixed and lifelong biological markers of any individual. They are almost as individual fingerprints (Ravn \& Dabelstein, 2000). Distribution of the ABO blood groups differs in populations throughout the universe (Garratty et al., 2000). In addition to clinical significance for transfusion and transplantation, it is becoming increasingly apparent that $\mathrm{ABO}$ antigens are of biological significance 
and may be associated with predisposition to, or protection from many diseases (Reid \& Bird, 1990). It has been reported by numerous authors that there is an association between blood group $\mathrm{O}$ and $H$. pylori infection (Kanbay et al., 2005), though, others failed to find such association (Niv et al., 1996). The ABO phenotype has been linked with stomach ulcers, which are more common in group $\mathrm{O}$ individuals and gastric cancer, which is more common in group A individuals (Iodice et al., 2010).

The relationship between $\mathrm{ABO}$ blood group-distribution and peptic ulcer disease (PUD) has been widely evaluated in the past, however, data concerning the same evaluation are very limited in Nigeria. This study was conducted to determine the distribution of the ABO blood group in patients with PUD among subjects attending Umaru-Shehu ultra-modern hospital, Maiduguri, Nigeria.

\section{METHODOLOGY}

\section{STUDY DESIGN}

The study was carried out at Umaru Shehu ultra-modern hospital, Maiduguri, Borno State, Nigeria. A random sampling technique was used to collect samples from fifty patients who presented symptoms of epigastric pain. Most of the patients seen at the hospital, who came from the city and surrounding districts, belong to the lower socio-economic class.

\section{ETHICAL APPROVAL}

Ethical approval was obtained from the Research and Ethics Committee of the Umaru Shehu Ultra-Modern Hospital, Maiduguri, Borno State, Nigeria. In addition, individual patients were intimated with the purpose of study and their consents were obtained before blood samples were collected for the study.

\section{COLLECTION OF SAMPLES}

A total of 50 blood samples were collected from patients with epigastric pain randomly without any specific pattern. A sterile syringe was used to collect the blood sample intravenously via the cephalic vein which was transferred immediately into the EDTA container and stored in a refrigerator at $2-8^{\circ} \mathrm{C}$ prior to the analysis.

\section{QUESTIONAIRE}

All the patients selected to participate in this were interviewed in detail and the data were recorded on a prescribed questionnaire. The data consisted of participants' demographic variables that include sex, age and blood group which are considered as risk factors for contracting $H$. pylori.

\section{DETERMINATION OF H. PYLORI ANTIBODY}

The H. pylori rapid test kit $(H$. pylori Antigen Rapid Test Cassette-CE-0123, UK) was used to determine the antibody. The simple tests (kit) utilized a combination of $H$. pylori antigen coated particles and anti-human $\operatorname{IgG}$ to qualitatively and selectively detect $H$. pylori antibodies in serum or plasma within few minutes.

\section{DETERMINATION OF BLOOD GROUP}

Blood groups of patients from whom samples were collected were determined using the Blood Grouping Sera Kit (Neutral Code: MH/DRUGS/25-KD/293: India). With the kit, A and B blood group-antigens, if present on surfaces of Red Blood Cells (RBCs) reacted with their complementary A and B antibodies in the serum leading to observable clump.

\section{STATISTICAL ANALYSIS}

The data were presented in frequency and percentage and analysed using Statistical Package for Social Science (SPSS version 22.0). Chi square ( $\chi 2)$ test was used to determine any significant relationship between sex/age/blood groups and the prevalence of $H$. pylori infection. Significance was established at $\mathrm{P} \leq 0.05$.

\section{RESULTS}

The results of sero-prevalence of $H$. pylori among patients with epigastric pain attending Umaru Shehu ultra-modern hospital showed that out of 50 serum samples tested, 45 $(90.0 \%)$ were positive. These included 10 (83.3\%) among males and $35(92.1 \%)$ among their female counterparts. However, no significant $(\mathrm{P}>0.05)$ difference was observed in association between the sex and the prevalence of the $H$. pylori infection (Table I).

Table I: Distribution of Helicobacter pylori infection among male and female patients with epi-gastric pain in Umaru Shehu hospital, Maiduguri, Nigeria

\begin{tabular}{lccc}
\hline Sex & Total & Positive & Positive (\%) \\
\hline Males & 12 & 10 & 83.3 \\
Females & 38 & 35 & 92.1 \\
\hline Total & 50 & 45 & 90 \\
\hline$($ P-value $>0.05)$ & & &
\end{tabular}

Age-distribution of $H$. pylori infection among patients with epigastric pain attending Umaru Shehu Ultra-Modern Hospital showed that three age groups 10-20 years, 31-40 year and $>50$ years had high prevalence of $100 \%$ with $10 / 10$, $7 / 7$ and $7 / 7$ ratios of positive to total tested number respectively (Table II). These were followed by patients between 21-30 years with $88.9 \%(16 / 18)$ and $41-50$ years with $62.5 \%$ (5/8). However, there was no significant $(\mathrm{P}>$ 0.05 ) association between the age and the prevalence of the H. pylori infection in the present study. 
Table II: Age-distribution of Helicobacter pylori infection among patients with epi-gastric pain in Umaru Shehu Hospital, Maiduguri, Nigeria.

\begin{tabular}{lccc}
$\begin{array}{l}\text { AGE } \\
\text { (Years) }\end{array}$ & Total & $\begin{array}{c}\text { Number } \\
\text { Positive }\end{array}$ & $\begin{array}{c}\text { Positive } \\
(\%)\end{array}$ \\
\hline $10-20$ & 10 & 10 & 100 \\
$21-30$ & 18 & 16 & 88.9 \\
$31-40$ & 7 & 7 & 100 \\
$41-50$ & 8 & 5 & 62.5 \\
$>50$ & 7 & 7 & 100 \\
\hline TOTAL & 50 & 45 & 90 \\
\hline
\end{tabular}

(P-value > 0.05)

The distribution of $\mathrm{ABO}$ blood groups and $H$. pylori infection demonstrated that positivity rate of $H$. pylori was $100 \%$ in blood group $\mathrm{AB}$ which had the highest prevalence in this study, followed by blood group A which had $95 \%$. Similarly, blood group O and B had $90.5 \%$ and $75 \%$ prevalence rate respectively as shown in Table III.

Table III: Blood group-distribution of Helicobacter pylori infection among patients with epi-gastric pain in Umaru Shehu hospital, Maiduguri, Nigeria

\begin{tabular}{lccc}
\hline $\begin{array}{l}\text { Blood } \\
\text { groups }\end{array}$ & Total & Positive & $\begin{array}{c}\text { Positive } \\
(\%)\end{array}$ \\
\hline $\mathrm{A}$ & 20 & 19 & 95 \\
$\mathrm{~B}$ & 8 & 6 & 75 \\
$\mathrm{AB}$ & 1 & 1 & 100 \\
$\mathrm{O}$ & 21 & 19 & 90.5 \\
\hline Total & 50 & 45 & 90 \\
\hline$(\mathrm{P}<0.05)$ & & & \\
\hline
\end{tabular}

\section{DISCUSSION}

In this study, 50 consenting epigastric patients were registered and screened for the presence of $H$. pylori antibodies after obtaining ethical approval from Hospital management and final consent from individual patients. The result showed that the prevalence rate of $H$. pylori infection among epigastric patients attending Umaru Shehu UltraModern Hospital, Maiduguri, North East Nigeria was 90.0\%. This figure is higher than the report from Khartoum, Sudan, which showed that $59.6 \% \mathrm{H}$. pylori prevalence in individuals with gastroesophageal reflux disease while $80 \%$ of nonpregnant patients with Barrett's esophagus were positive for H. pylori (Ahmed, 2004). It is also higher than $H$. pylori positivity ratio of $59.0 \%$ got in the Ikeja, Lagos, Nigeria (Mynepalli \& Mumuni, 2014). The prevalence of $H$. pylori obtained in the present study is also higher than other results elsewhere such as 50-70\% in Turkey (Karaer et al., 2008), Mexico and Texas, United States (Felkner et al., 2007) as well as $80 \%$ in Gambia (Bunn et al., 2003).

The high rate of $H$. pylori infection in this study agrees with the observation of $88 \%$ rate of $H$. pylori infection in Egypt (Bassily et al., 1999). Similarly, the result of this study is higher than the prevalence of $17.5 \%$ observed among pregnant women in the African Island of Zanzibar (Farag, 2007). Outside African continent, the prevalence of 20-30\% of $H$. pylori infection was reported among pregnant women in most European countries (Weyermann et al., 2005; Cardaropoli et al., 2013), Japan (Kitagawa et al., 2001) and Australia (Erskine et al., 1978). This might be a result of overcrowding or difference in hygienic practices or other socio-demographic features. A lower (compared to our results) but higher prevalence for a developed nation (74\%) of $H$. pylori infection was reported among pregnant women at the US-Mexico border (Goodman et al., 2003).

The prevalence of $H$. pylori infection in epigastric patients varies according to their geographical areas, socio-economic conditions and method used to detect $H$. pylori infection. Furthermore, inadequate sanitation practices, low social class and crowded or high-density living conditions seem to be related to a higher prevalence of $H$. pylori infection. These observations suggest that poor hygiene and crowded conditions may facilitate the transmission of infection among family members and they are consistent with data on intrafamilial and institutional clustering of $H$. pylori (Cardaropoli et al. 2014).

Distribution of $H$. pylori according to sex in this study demonstrated that the female has the highest prevalence of $92.1 \%$ as compared to their male counterpart which was $83.3 \%$. These results on gender disagree with report of Ndip et al. (2004) which associated males with higher risk of acquiring $H$. pylori infection than females. On the other hand and in contrast to our results, other researchers have reported the same rate of infection in both male and females (Nwodo et al. 2009, Rasmi et al. 2009).

The youngest, middle and oldest age groups in this study had maximum prevalence of $100 \%$. And these findings disagree with report of Özden et al. (2004) which had emphasized that $H$. pylori positivity ratio decrease with increasing ages. This is quite reasonable since adult individuals tend to be more hygienic than young ones. However, our results are similar to the previous study of Jaff (2011) which documented the distribution of $H$. pylori positive (+) frequency according to age groups to be $96 \%$ in subject between 7 - 12 age group, $83 \%$ between 13 - 18 age group, $75 \%$ between 19 - 24 age group, $96 \%$ between 25 - 29 age group, $91 \%$ between 30 - 34 age group, $83 \%$ between 35 - 39 
age group, and $94 \%$ between 40 - 65 age group. Comparing the latter results with the results of the present study, it seems the $H$. pylori infection is higher in the minimum, middle and maximum age groups and never follows a straight pattern of decreasing infection with increasing age or vice versa.

The distribution of $H$. pylori according to $\mathrm{ABO}$ blood groups among epigastric patients showed that there was a significant association between $\mathrm{ABO}$ blood groups and $H$. pylori infection. The Blood group $\mathrm{AB}$ has a greater tendency towards the infection with the highest prevalence of $100 \%$, followed by A, O and B with a prevalence of $95 \%, 90 \%$ and $75 \%$ respectively. This study disagrees with the reports of Dhillon and Shergill, (2004) and Martins et al. (2006) studies, where higher prevalence of $H$. pylori was recorded among patients with blood group $\mathrm{O}(46.7 \%)$ as compared with A (20\%), B (13.3\%) and AB (3.3\%) blood groups with statistical significant difference among the blood group categories.

Limitations of this study have to do with small sample size as well as uneven sampling number across various groups. The higher sample size of some group categories against the other such as blood group $\mathrm{AB}$ with just one sample could not be predetermined prior to collection of the blood sample. However, further studies involving larger sample size are suggested which will possibly increase the number of patient with various categories.

\section{CONCLUSION}

Results of this study show high prevalence of $H$. pylori infection (90.0\%) among patients complaining of epigastric pain in Maiduguri, Nigeria. No significant association was established between age/sex and $H$. pylori infection, whereas a significant association was observed with blood group. Therefore, H. pylori infection should be screened in such patients particularly those that are in clusters with inadequate sanitation such as internally displaced people living in camps.

\section{REFERENCES}

Ahmed, H. H., Mudawi, H. M. \& Fedail, S. S. (2004). Gastro-oesophageal reflux disease in Sudan: a clinical endoscopic and histopathological study. Tropical gastroenterology, 25(3), 135-138.

Alvarado-Esquivel, C. (2013). Seroepidemiology of Helicobacter pylori infection in Tepehuanos aged 15 years and older in Durango, Mexico. Journal of Pathogens, 2013.

Bassily, S., Frenck, R. W., Mohareb, E. W., Wierzba, T., Savarino, S., Hall, E. \& Clemens, J. (1999). Seroprevalence of Helicobacter pylori among Egyptian newborns and their mothers: a preliminary report. The American journal of tropical medicine and hygiene, 61(1), 37-40.

Dhillon, B. S. \& Shergill, S. S. (2004). Prevalence of ABO and $\mathrm{Rh}$ blood groups in colour vision defective
Punjabi population. North Zone Ophthalmological Society Journal, 1, 2-4.

Erskine, A. G. \& Socha, W. W. (1978). Principles and practice of blood grouping. Mosby

Forman, D., Sitas, F., Newell, D. G., Stacey, A. R., Boreham, J., Peto, R. \& Chen, J. (1990). Geographic association of Helicobacter pylori antibody prevalence and gastric cancer mortality in rural China. International Journal of Cancer, 46(4), 608-611.

Garratty, G., Dzik, W., Issitt, P. D., Lublin, D. M., Reid, M. E., \& Zelinski, T. (2000). Terminology for blood group antigens and genes-historical origins and guidelines in the new millennium. Transfusion, 40(4), 477-489.

Goodman, K. J. \& P. Correa. (2000). Transmission of Helicobacter pylori among siblings. Lancet, 355, 358-362.

International Agency for Research on Cancer. (1994). Monographs on the evaluation of carcinogenic risks to human schistosomes, liver flukes and Helicobacter pylori. International Agency for Research on Cancer, 61, 3-12.

Iodice, S., Maisonneuve, P., Botteri, E., Sandri, M. T., \& Lowenfels, A. B. (2010). ABO blood group and cancer. European journal of cancer, 46(18), 33453350 .

Jaff, M. S. (2011). Relation between ABO blood groups and Helicobacter pylori infection in symptomatic patients. Clinical and experimental gastroenterology, 4, 221.

Kanbay, M. Gur, G. Arslan, H. Yilmaz, U. \& Boyacioglu ,S. (2005). The relationship of ABO blood group, age, gender, smoking and Helicobacter pylori infection, Digestive Disease Science, 50 (7), 1214-1217.

Martins, L. C., de Oliveira Corvelo, T. C., Oti, H. T., Loiola, R. D. S. P., Aguiar, D. C. F., dos Santos Barile, K. A.,\& de Souza, J. T. (2006). ABH and Lewis antigen distributions in blood, saliva and gastric mucosa and $\mathrm{H}$. pylori infection in gastric ulcer patients. World journal of gastroenterology, 12(7), 1120.

Morris, A. J., Ali, M. R., Nicholson, G. I., Perez-Perez, G. I., \& Blaser, M. J. (1991). Long-term follow-up of voluntary ingestion of Helicobacter pylori. Annals of internal medicine, 114(8), 662-663.

Ndip, R. N., Malange, A. E., Akoachere, J. F. T., MacKay, W. G., Titanji, V. P. K. \& Weaver, L. T. (2004). Helicobacter pylori antigens in the faeces of asymptomatic children in the Buea and Limbe health districts of Cameroon: a pilot study. Tropical Medicine \& International Health, 9(9), 1036-1040.

Ravn, V. \& Dabelstein, E. (2000). The ABO blood group system: historical background. Translatioinal Medicine, 11, 243-262.

Reid, M.E. \& Bird, G.W. (1990). Associations between human red cell blood group antigens and disease, Transfusion Medical Review, 4(1), 47-55.

Article history: Received: Sept. 4, 2021,

Revised: Sept. 19, 2021, Accepted: Sept. 20, 2021 